\title{
Maternal and perinatal outcome in severe pre-eclampsia and eclampsia: a study of 120 cases at a tertiary health care center in Western India
}

\author{
Akash J. Patel*, Babulal S. Patel, Akshay C. Shah, Shashwat K. Jani \\ Department of Obstetrics and Gynecology, NHL Municipal Medical College, Ahmedabad, Gujarat, India \\ Received: 30 December 2020 \\ Accepted: 05 February 2021 \\ *Correspondence: \\ Dr. Akash J. Patel, \\ E-mail: hsakapatel25@gmail.com \\ Copyright: (c) the author(s), publisher and licensee Medip Academy. This is an open-access article distributed under \\ the terms of the Creative Commons Attribution Non-Commercial License, which permits unrestricted non-commercial \\ use, distribution, and reproduction in any medium, provided the original work is properly cited.
}

\begin{abstract}
Background: Hypertensive disorders of pregnancy are a leading cause of maternal and perinatal mortality and morbidity worldwide. Pre-eclampsia accounts for the majority of referrals in a tertiary care center as it stands one of the major causes of maternal and perinatal morbidity and mortality. It complicates $6-10 \%$ of all pregnancies. In India, they account for the third most important cause of maternal mortality. Patients with PIH are at a greater risk of abruptio placenta, cerebrovascular events, organ failure and DIC. Fetuses are at a greater risk of IUGR, preterm birth, small for gestational age and IUD. This study aimed to determine the maternal and perinatal outcomes of hospitalized pregnant cases with severe preeclampsia and eclampsia.

Methods: This was a single year retrospective study conducted in a tertiary care center of Western India from May 2019 to May 2020. Maternal and perinatal outcomes were analyzed among the severe preeclampsia and eclampsia groups.

Results: A total $52(43.33 \%)$ of the cases were in the age group of 21-25 years, $64(53.33 \%)$ were primigravidae and the majority were referred from peripheral hospitals. Liver function tests were deranged in $26.68 \%$ of the patients and $32.5 \%$ had abnormal renal function. Labetalol was the most commonly used antihypertensive and magnesium sulphate was the anticonvulsant used in all the cases. Lower segment caesarean section was the mode of delivery in $62(51.67 \%)$ of the cases. Commonest maternal complication was atonic PPH (12.5\%). There was one maternal mortality due to aspiration pneumonia. 85 (70.83\%) of the babies needed NICU admission. There were $5(4.16 \%)$ perinatal deaths.

Conclusions: Accessible health care and health education and awareness regarding antenatal check-ups for all women will lead to early detection of severe preeclampsia. Prompt treatment and management of its complications will certainly improve the maternal and fetal outcome.
\end{abstract}

Keywords: Preeclampsia, Eclampsia, Maternal morbidity, Maternal mortality, Perinatal morbidity, Perinatal mortality

\section{INTRODUCTION}

Hypertensive disorders of pregnancy (HDP) account for nearly $18 \%$ of all maternal deaths worldwide, with an estimated 62 000-77 000 deaths per year. ${ }^{1}$ An estimated 287000 maternal deaths occurred in 2010, with a wide variation across regions with regard to their lifetime risk (from 1 in 3800 in developed countries to 1 in 39 in subSaharan Africa). ${ }^{2}$ In India hypertensive disorders account for the third most important cause of maternal mortality. ${ }^{3}$ They are associated with significant maternal and perinatal morbidity and mortality and have a wide spectrum of presentation, ranging from minimal elevation of blood pressure to severe hypertension with multiple organ dysfunctions. Among the hypertensive disorders, the pre-eclampsia syndrome, either alone or superimposed on chronic hypertension, is the most dangerous. Eclampsia is the convulsive form of pre- 
eclampsia and affects $0.1 \%$ of all the pregnancies. ${ }^{4} \mathrm{New}$ onset non protein uric hypertension during pregnancy, termed gestational hypertension, is followed by signs and symptoms of pre-eclampsia almost half the time. Women who develop pre-eclampsia in pregnancy are at greater risk of cardiovascular and cerebrovascular events even years after their pregnancies. Hypertension complicating pregnancy is a major cause of preterm births resulting in perinatal deaths of foetuses. In low income and middleincome countries, pre-eclampsia and eclampsia are associated with $10-15 \%$ of direct maternal deaths. WHO estimates the incidence of preeclampsia to be seven times higher in developing countries $(2.8 \%$ of live births) than in developed countries $(0.4 \%){ }^{5}$

Incidence of eclampsia in developing nations varies widely, ranging from 1 case per 100 pregnancies to 1 case per 3448 pregnancies. For patients obtaining prenatal care, the incidence is about 1 in 800 patients. 6 The proportion of women surviving severe maternal complications (also called 'near-miss' cases) has been proposed as a useful gauge for the evaluation of the quality of maternal health care and its determinants, with the potential to complement the information obtained from the reviews of maternal deaths. ${ }^{7,8}$

\section{Definitions}

Preeclampsia: Preeclampsia is a multisystem, multifactorial disease defined as blood pressure (B.P) reading of $\geq 140 / 90 \mathrm{mmHg}$ on two occasions 4 hours apart and $>0.3 \mathrm{~g}$ protein in 24-hour urine specimen after 20 weeks of gestation in a previously normotensive woman.

Severe preeclampsia: Severe preeclampsia is B.P reading of $\geq 160 / 110 \mathrm{mmHg}$ and $>5 \mathrm{~g}$ protein in 24-hour urine specimen or symptoms of end organ damage like deranged LFT, thrombocytopenia, oliguria, visual disturbances, pulmonary oedema etc.

Eclampsia: Eclampsia is defined as generalised tonic clonic seizures and /or unexplained coma in a woman with preeclampsia.

The present analysis has been done to analyse the perinatal and maternal outcome in severe preeclampsia and eclampsia and other factors associated it.

In spite of advances in medicine, preeclampsia and eclampsia continue to remain leading causes of maternal and perinatal mortality and morbidity throughout the world. Severe preeclampsia can lead to multiple lifethreatening complications like eclampsia, cerebral haemorrhage, cardiovascular complications, hepatic failure, acute renal failure, pulmonary oedema, ARDS (adult respiratory distress syndrome), DIC (disseminated intravascular coagulation) HELLP syndrome (haemolysis, elevated liver enzymes, low platelet), retinal detachment, cortical blindness, hypoxic cerebral damage and even maternal death.

Fetal complications are mainly due to uteroplacental insufficiency leading to IUGR (intrauterine growth restriction), low birth weight babies, IUFD (intrauterine fetal death) and complications due to prematurity. There are still no widely accepted biochemical markers for early detection of Preeclampsia but some maternal and pregnancy characteristics have been identified as risk factors, these are nulliparity, previous history of preeclampsia, maternal age over 40, multiple gestation, molar pregnancy, pre-gestational diabetes, vascular, endothelial or renal diseases, maternal smoking, obesity and certain genetic factors. ${ }^{9}$

\section{METHODS}

This research is a 1-year retrospective study of randomly selected severe preeclampsia and eclampsia cases in Sardar Vallabhbhai Patel hospital and Sheth V.S. municipal medical college and Sheth C. M. hospital, Ahmedabad from May 2019 to May 2020. A total of 120 women with severe pre-eclampsia and eclampsia were included in the study and their case records were retrospectively analysed.

\section{Inclusion criteria}

B.P reading of $\geq 160 / 110 \mathrm{mmHg}$ with $1+$ or more albuminuria was the criteria followed for categorising severe preeclampsia. Eclampsia was presence of seizures in women with preeclampsia which could not be attributed to other causes.

\section{Exclusion criteria}

Patients with chronic hypertension (before 20 weeks of gestation), chronic renal disease, connective tissue disorders and mild preeclampsia, diabetes, vascular diseases, multiple gestation, polyhydramnios, gestational trophoblastic neoplasia.

Patients with medical complications like anaemia, preexisting hypertensive, diabetes, vascular or renal disease, multiple gestation, polyhydramnios, GTN were excluded from the study. The outcome of each pregnancy was obtained by examining the patient in labour ward and neonates in neonatal intensive care unit.

On admission detailed demographic, personal, medical, obstetric and family history was recorded from the patient or her attendant as appropriate. General physical examination, systemic, abdominal and pelvic examinations were carried out. Investigations like complete blood count with absolute platelet count, liver function tests, renal function tests, coagulation profile, and fundoscopy and urine examination were performed or all patients. Ultrasound was done at the time of admission after patient stabilization. 
Management was carried out as per department protocol. Corticosteroids were administered if gestational age was less than 34 weeks gestation. The decision regarding timing and mode of delivery were individualized. Eclamptic patients were given magnesium sulphate by Pritchard's regimen; anti-hypertensive drugs were nifedipine, methyldopa, and labetalol singly or in combination. Obstetric management was done (spontaneous/ induced labor) as per the unit protocols and patients were delivered either by vaginal route or by cesarean section. Neonatal care was provided by pediatrician from delivery onwards. The patients with uncontrolled hypertension were managed in collaboration with physician and anaesthetist.

The statistical analysis was done in Microsoft excel 2019.

\section{RESULTS}

In this study, records of 8740 women who delivered in our tertiary hospital were reviewed and of these, 728 women had hypertensive disorders of pregnancy. Of these cases with patients with severe preeclampsia and eclampsia (n-120) were taken into the study.

We had 87 (72.5\%) patients between 20-30 years of age followed by $15 \%$ patients beyond 35 years of age. Majority of our patients were primigravida (53.33\%). Majority patients $(70 \%)$ presented before 37 completed weeks of gestation (Table 1).

Table 1: Demographic and antenatal background.

\begin{tabular}{|ll|}
\hline Variables & Cases $(\%)$ \\
\hline Age (years) & \\
\hline$<20$ & $5(4.17)$ \\
\hline $21-25$ & $52(43.33)$ \\
\hline $26-30$ & $35(29.17)$ \\
\hline $31-35$ & $10(8.33)$ \\
\hline$>35$ & $18(15)$ \\
\hline Parity & \\
\hline Primigravida & $64(53.33)$ \\
\hline Multigravida & $36(30)$ \\
\hline Grand multipara & $20(16.67)$ \\
\hline Gestation (weeks) & \\
\hline$<28$ & $4(3.33)$ \\
\hline $29-32$ & $15(12.5)$ \\
\hline $33-36$ & $65(54.16)$ \\
\hline$>37$ & $36(30)$ \\
\hline
\end{tabular}

Majority of the patients had headache $(45 \%)$ as a chief complain. Liver functions were deranged where $12.5 \%$ cases had SGOT> 100 IU and another $14.17 \%$ cases had SGPT $>100$ IU. Renal functions were deranged in $32.5 \%$ of our patients, who most commonly had raised serum creatinine levels. Majority of patients (56.67\%) had proteinuria level of $>+3$.
Majority of the patients $(51.67 \%)$ were delivered through LSCS in view of failed induction or non-progress as well as other indications like previous caesarean, oligohydramnios and cephalopelvic disproportion. However, $46.67 \%$ patients delivered vaginally 2 hysterectomy were done-1 during caesarean section and the other after normal vaginal delivery due to post-partum hemorrhage (Table 3).

Table 2: Signs and symptoms.

\begin{tabular}{|ll|}
\hline Signs and symptoms & Cases $(\%)$ \\
\hline Headache & $54(45)$ \\
\hline Convulsion & $17(14.16)$ \\
\hline Epigastric pain & $8(6.67)$ \\
\hline Vomiting & $17(14.17)$ \\
\hline Pedal edema & $34(28.33)$ \\
\hline Generalized edema & $1(0.83)$ \\
\hline Blurring of vision & $9(7.5)$ \\
\hline Oliguria & $12(10)$ \\
\hline
\end{tabular}

Table 3: Mode of delivery.

\begin{tabular}{|l|l|}
\hline Variables & Cases (\%) \\
\hline Vaginal & $56(46.67)$ \\
\hline $\begin{array}{l}\text { Lower segment caesarean } \\
\text { section }\end{array}$ & $62(51.67)$ \\
\hline Hysterectomy & $2(1.6)$ \\
\hline
\end{tabular}

Most common indication for operative intervention was previous caesarean section $(30.64 \%)$ followed by oligohydramnios (16.13\%) and cephalopelvic disproportion $(16.13 \%)$ in our study. 2 cases of abruption were there (Table 4).

Table 4: Indication for caesarean delivery.

\begin{tabular}{|ll|}
\hline Indication severe PIH + & Cases $(\%)$ \\
\hline Previous caesarean & $19(30.64)$ \\
\hline Oligohydramnios & $10(16.13)$ \\
\hline Cephalo-pelvic disproportion & $10(16.13)$ \\
\hline Induction failure & $8(12.9)$ \\
\hline Fetal distress & $7(11.3)$ \\
\hline Abruption & $2(3.23)$ \\
\hline IUGR/doppler changes & $6(6.67)$ \\
\hline
\end{tabular}

All the patients were given magnesium sulphate prophylactically as well as therapeutically depending upon the need. Antihypertensive used for management were nifedipine and labetalol. Combination of both drugs was given in $27.5 \%$ cases. With labetalol in 48 (40\%) cases.

Most common maternal complication was post-partum haemorrhage $(12.5 \%)$. There were $17(14.16 \%)$ cases of eclampsia in the study. All the cases were treated with magnesium sulphate. HELLP syndrome was seen in 1 case. Near- miss cases were there in 3 cases with DIC. 
There was 1 maternal mortality due to aspiration pneumonia (Table 5).

Table 5: Maternal complication.

\begin{tabular}{|ll|}
\hline Complication & Cases $(\%)$ \\
\hline Post-partum hemorrhage & $15(12.5)$ \\
\hline Abruptio placentae & $2(1.67)$ \\
\hline Pulmonary edema & $2(1.67)$ \\
\hline Pulmonary embolism & $1(0.83)$ \\
\hline Renal dysfunction & $10(8.33)$ \\
\hline HELLP syndrome & $1(0.83)$ \\
\hline ARDS & $4(3.33)$ \\
\hline Neurological dysfunction & $3(2.5)$ \\
\hline Eclampsia & $17(14.16)$ \\
\hline DIC & $3(2.5)$ \\
\hline Mortality & $1(0.83)$ \\
\hline
\end{tabular}

$70.83 \%$ cases required NICU admission. $68.93 \%$ neonates were born prematurely out of which 19 $(15.83 \%)$ had respiratory distress syndrome. 25 (20.83\%) neonates had very low birth weight ( $<1500 \mathrm{gm})$. Perinatal mortality was found to be $4.16 \%$ with which included IUFD after 28 weeks in 2 , still birth in 1 and early neonatal death in 2 cases (Table 6).

Table 6: Perinatal outcome.

\begin{tabular}{|ll|}
\hline Complication & Cases (\%) \\
\hline Total birth & 120 \\
\hline Live birth & $115(89.16)$ \\
\hline IUFD & $4(3.33)$ \\
\hline Still birth & $1(0.83)$ \\
\hline Early neonatal death & $2(1.67)$ \\
\hline Perinatal death & $5(4.16)$ \\
\hline NICU admission & $85(70.83)$ \\
\hline Prematurity & $82(68.93)$ \\
\hline IUGR & $17(14.16)$ \\
\hline Respiratory distress syndrome & $19(15.83)$ \\
\hline Birth weight & \\
\hline$>1500-<2500$ gm & $51(42.5)$ \\
\hline$<1500$ gm & $25(20.83)$ \\
\hline
\end{tabular}

\section{DISCUSSION}

The most common medical entity faced in pregnant women is hypertension, and it causes significantly adverse maternal and foetal outcomes. ${ }^{10}$ It affects about $10 \%$ of all pregnancies. ${ }^{11}$ Pregnancies complicated by hypertension are associated with increased risk of antagonistic foetal, neonatal, and maternal consequences, comprising of intrauterine growth restriction, preterm birth, post or antepartum haemorrhage, acute renal and hepatic failure and lastly maternal and perinatal death. ${ }^{12}$

In the present study, out of the 120 cases of severe preeclampsia and eclampsia, 64 were primigravidae and 5 were less than 20 years of age. The highest number of cases was in the age group of 26-30 years. Severe preeclampsia was seen more commonly in primigravidae. Other studies notably by Sibai and Cunningham also support this view. ${ }^{13}$ Nulliparity as a separate risk factor for severe preeclampsia has been reported in studies by Saxena et al in India and by CondeAgudelo in Latin American women. ${ }^{14,15}$ Ketz et al reported $70 \%$ of their patients as primigravidas. ${ }^{16} 66.67 \%$ of cases had gestational age between 29 to 36 weeks and $30 \%$ of patients had term pregnancy. Singhal et al also reported similar findings. ${ }^{17}$

Liver functions were deranged in $26.68 \%$ of our cases and renal functions were deranged in another $32.5 \%$ whereas in a study done by Singhal et al showed that $20 \%$ patients had deranged liver function tests while $27 \%$ patients had deranged renal functions. $14.17 \%$ patients had low haemoglobin which was due to complications like abruption placentae, DIC and HELLP. 5\% patients also had elevated bilirubin and $3.33 \%$ low platelet counts. PT INR was deranged in $11.67 \%$ patients who were managed by giving FFP transfusions.

The most common mode of delivery was lower segment caesarean section in $51.67 \%$ of the cases and the most common indication was previous one or more caesarean sections. The mode of delivery was determined by severity of maternal condition, Bishop's score, gestational age, fetal condition, USG and laboratory investigations. Singhal et al reported $33 \%$ caesarean section rate. ${ }^{17}$ Tufnell et al reported as high as $72 \%$ caesarean section rate in BJOG. ${ }^{18}$ Caesarean section rates of 71 and $78 \%$ respectively were reported by Miguel et al and Dissanayake et al. ${ }^{19,20}$ The high rate of caesarean section in the present study is due to more than $30.64 \%$ cases being previous caesarean section and also due to emergency delivery approach taken to prevent further maternal and fetal complications due to severe preeclampsia or eclampsia especially in cases where the cervix is unfavourable for induction. $5.35 \%$ of cases had LSCS for reversed or absent end diastolic flow in umbilical artery. Uteroplacental insufficiency seen in severe preeclampsia and eclampsia is the major cause of IUGR seen in $14.16 \%$ of the cases in the present study.

The main factors determining maternal morbidity are associated risk factors like diabetes, anaemia, nulliparity, advanced maternal age, early onset preeclampsia, severe preeclampsia and previous history of preeclampsia. Maternal complications included PPH in 15 cases (12.5\%) followed by renal dysfunction in 10, abruption in 2, HELLP in 4, DIC in 3, pulmonary edema in 2, pulmonary embolism in 1 and maternal death in 2 cases. Abruption was seen in 9 cases in the study by Shaikh et al and Murphy's. Whereas another study done by Singhal et al showed only one case had abruption. A study by Farid et al had $11 \%$ incidence of HELLP syndrome and $10 \%$ incidence of abruptio placenta. ${ }^{21}$ In a ten-year study done by Igberase et al the important causes of maternal mortality in severe preeclampsia were acute renal failure, 
disseminated intravascular coagulopathy (DIC), cardiac arrest, pulmonary edema and cerebrovascular accidents. ${ }^{22}$

Prematurity was the most common complication among the neonates seen in $68.93 \%$ of the cases. Tufnell et al reported $65.3 \%$ incidence of prematurity. ${ }^{18}$ The high incidence of preterm delivery could be attributed to the early intervention and induction of labour or LSCS done to avert further maternal and perinatal complications. Perinatal mortality was seen in $5(4.16 \%)$ cases which included IUFD after 28 weeks in 2, still birth in 1 and early neonatal deaths in 2 cases. Study by Shaikh et al showed IUD in 14, neonatal death in 18 cases and perinatal loss of $38.6 \%$. Neonatal deaths were mostly due to extreme prematurity and its complications. Patients of eclampsia had more dreadful complications as compared to severe pre-eclampsia. These findings are in good agreement with observations by study done by Singhal et al. ${ }^{17}$

\section{Limitations}

As the sample size in the present study is limited, it cannot be applied to generalized population. Both the fetal and maternal outcome might vary in different hospital settings.

\section{CONCLUSION}

Preeclampsia and eclampsia continue to be significant causes of maternal and fetal morbidity and mortality. The study states that, postpartum haemorrhage and more operative interference in mothers, with prematurity as the most commonly encountered perinatal outcome and low birth weight being the most common neonatal outcome. The main factors determining maternal morbidity are associated risk factors like diabetes, anaemia, nulliparity, advanced maternal age, early onset preeclampsia, severe preeclampsia and previous history of preeclampsia. provision of quality antenatal health care services, increasing patient awareness about warning symptoms, investigations, timely delivery and intensive monitoring in the intrapartum and postpartum period have the potential to improve maternal and perinatal outcome.

Funding: No funding sources

Conflict of interest: None declared

Ethical approval: The study was approved by the Institutional Ethics Committee

\section{REFERENCES}

1. Khan KS, Wojdyla D, Say L, Gulmezoglu AM, Van Look PF. WHO analysis of causes of maternal death: a systematic review. Lancet. 2006;367:1066-74.

2. World Health Organization, UNICEF, UNFPA and the World Bank. Trends in Maternal Mortality: 1990 to 2010. Geneva: World Health Organization, 2012. World Health Organization: http://whqlibdoc.who.int/publications/2012/9789241

503631_eng.pdf. Accessed 12 June 2013.

3. Govt. of India (Sample Registration System) Maternal mortality in India, 1997-2003. Trends, causes and risk factors. Registrar General of India, New Delhi in collaboration.

4. Berzan E, Doyle R, Brown CM. Treatment of preeclampsia: current approach and future perspectives. Curr Hypertens Rep. 2004;16(9):473.

5. World Health Organisation. The world health report 2005- Make every mother and child count. World Health Organization, Geneva. 2005.

6. Wilkins LW. Hypertensive disorders in pregnancy. In: Barton JR, et al. (Eds.), Manual of Obstetrics. $8^{\text {th }}$ edn. Wolters Kluver Health, Philadelphia, USA. 2014;183-95.

7. Say L, Souza JP, Pattinson RC. WHO Working Group on Maternal Mortality and Morbidity Classifications. Maternal near miss-towards a standard tool for monitoring quality of maternal health care. Best Pract Res Clin Obstet Gynaecol. 2009;23:287-96.

8. Pattinson R. Near miss audit in obstetrics. Best Pract Res Clin Obstet Gynaecol. 2009;23:285-6.

9. Conde-Agudelo A, Villar J, Lindeheimer M. World Health Organization systematic review of screening tests for preeclampsia. Obstet Gynecol. 2004;104(6):1367-91.

10. National high blood pressure education program working group, report on high blood pressure in Pregnancy. Am J Obstetr Gynaecol. 1990;163:1691712.

11. Liu CM, Cheng PJ, Chang SD. Maternal Complications and Perinatal Outcomes associated with Gestational Hypertension and Severe Preeclampsia in Taiwanese Women. J Formes Med Asso. 2008;107(2):129-38.

12. Josephine Latha P, Ganesan S. Evaluation of serum uric acid and lipid profile in gestational hypertension. Int J Pharm Bio Sci. 2013;4(2):(B)496-502.

13. Sibai BM, Cunningham FG. Prevention of preeclampsia and eclampsia. In: Lindheimer MD, Roberts JM, Cunningham FG, editors. Chesley's Hypertensive Disorders of Pregnancy. $3^{\text {rd }}$ Ed. New York: Elsevier. 2009;215.

14. Saxena S, Srivastava PC, Thimmaraju KV, Mallick AK, Dalmia K, Das B. Socio-demographic profile of pregnancy induced hypertension in a tertiary care centre. Sch J Appl Med Sci. 2014;2:3081-6.

15. Conde-Agudelo A, Belizán JM. Risk factors for preeclampsia in a large cohort of Latin American and Caribbean women. BJOG. 2000;107:75-83.

16. Katz VL, Farmer R, Kuller JA. Pre-eclampsia into eclampsia: toward a new paradigm. Am J Obstet Gynecol. 2000;182:1389-96.

17. Singhal S, Deepika, Anshu, Nanda S. Maternal and perinatal outcome in severe pre-eclampsia and eclampsia. South Asian Federation Obstet Gynecol. 2009;1(3):25-8. 
18. Tufnell DJ, Jankowicz D, Lindow SW, Lyons G, Mason GC, Russell IF et al. Outcome of severe preeclampsia/eclampsia. Yorkshire 1999/2003. Br J Obstet Gynecol. 2005;112:875-80.

19. Miguil M, Chekairi A. Eclampsia, study of 342 cases. Hypertens Pregnancy. 2008;27(2):103-11.

20. Dissanayake VH, Samarasinghe HD, Morgan L, Jayasekara RW, Seneviratne HR, Pipkin FB. Morbidity and mortality associated with preeclampsia at two tertiary care hospitals in Sri Lanka. J Obstet Gynaecol Res. 2007;33(1):56-62.
21. Mattar F, Sibai BM. Risk factors for maternal morbidity. Am J Obstet Gynecol. 2000;182:307-12.

22. Igberase GO, Ebeigbe PN. Eclampsia: ten-years of experience in a rural tertiary hospital in the Niger delta, Nigeria. J Obstet Gynecol. 2006; 26(5):414-7.

Cite this article as: Patel AJ, Patel BS, Shah AC, Jani SK. Maternal and perinatal outcome in severe pre-eclampsia and eclampsia: a study of 120 cases at a tertiary health care center in Western India. Int $\mathbf{J}$ Reprod Contracept Obstet Gynecol 2021;10:1011-6. 